Апnи Rev Genet. 2010 ; 44: 91-112. doi:10.1146/annurev-genet-102209-163600.

\title{
Evolution of Sex Chromosomes in Insects
}

\author{
Vera B. Kaiser and Doris Bachtrog \\ Department of Integrative Biology, University of California Berkeley, Berkeley, California 94720 \\ Vera B. Kaiser: vera.kaiser@berkeley.edu; Doris Bachtrog: dbachtrog@berkeley.edu
}

\section{Abstract}

Sex chromosomes have many unusual features relative to autosomes. Y (or W) chromosomes lack genetic recombination, are male- (female-) limited, and show an abundance of genetically inert heterochromatic DNA but contain few functional genes. $\mathrm{X}$ (or Z) chromosomes also show sexbiased transmission (i.e., $\mathrm{X}$ chromosomes show female-biased and Z-chromosomes show malebiased inheritance) and are hemizygous in the heterogametic sex. Their unusual ploidy level and pattern of inheritance imply that sex chromosomes play a unique role in many biological processes and phenomena, including sex determination, epigenetic chromosome-wide regulation of gene expression, the distribution of genes in the genome, genomic conflict, local adaptation, and speciation. The vast diversity of sex chromosome systems in insects-ranging from the classical male heterogametic XY system in Drosophila to ZW systems in Lepidoptera or mobile genes determining sex as found in house flies-implies that insects can serve as unique model systems to study various functional and evolutionary aspects of these different processes.

\section{Keywords}

$\mathrm{Y}$ degeneration; dosage compensation; meiotic sex chromosome inactivation; faster $\mathrm{X}$ evolution; sex-biased genes

\section{THE EVOLUTION OF HETEROMORPHIC SEX CHROMOSOMES}

In many eukaryotic organisms, the two sexes have different chromosomal constitutions. Typically, one sex (called heterogametic) has a pair of morphologically different chromosomes, and the other sex (called homogametic) has two identical members of each chromosomal pair. In species with male heterogamety, the sex chromosomes are referred to as $\mathrm{X}$ and $\mathrm{Y}$ chromosomes (XX females and $\mathrm{XY}$ males), whereas they are termed $\mathrm{Z}$ and $\mathrm{W}$ chromosomes in species with female heterogamety (ZZ males and ZW females). For simplicity and when discussing general facets of sex chromosome evolution, we will refer to the more familiar XY chromosome systems, but the same evolutionary principles discussed apply to ZW systems, with the appropriate change in notation.

\section{DISCLOSURE STATEMENT}

The authors are not aware of any affiliations, memberships, funding, or financial holdings that might be perceived as affecting the objectivity of this review. 
Morphologically and genetically distinct $\mathrm{X}$ and $\mathrm{Y}$ chromosomes involved in sex determination have evolved independently many times in both animals and plants $(32,42)$. It is generally believed that the $\mathrm{X}$ and $\mathrm{Y}$ chromosomes originated from an initially identical chromosome pair, with morphological differentiation being a by-product of the degeneration of the chromosome that is present only in the heterogametic sex (i.e., the Y chromosome in species with $\mathrm{XY}$ males and $\mathrm{XX}$ females) and thus is completely sheltered from genetic recombination $(26,45,47)$. The steps leading to the evolution of suppressed recombination between nascent $\mathrm{X}$ and $\mathrm{Y}$ chromosome are outlined in Figure 1.

Evolutionary theory predicts that a nonre-combining genome is vulnerable to an accumulation of deleterious mutations and will show lower rates of adaptation (discussed in detail in $11,24,43,45,49,56,62$ ). Indeed, a striking common feature of many taxa is the almost complete erosion of genes from the $\mathrm{Y}$ chromosome. The $\mathrm{Y}$ also often contains an unusual abundance of repetitive DNA sequences. It thus presents the bizarre phenomenon of a major part of the genome consisting largely of nonfunctional DNA. X chromosomes, in contrast, retain most of their ancestral genes but have evolved unique features to face their unusual challenges relative to autosomes. First, the loss of gene function on the $\mathrm{Y}$ creates a gene dose discrepancy for $\mathrm{X}$-linked genes in males. To compensate for gene dose deficiencies, $\mathrm{X}$ chromosomes have acquired elaborate mechanisms of dosage compensation (DC) $(42,100)$. Second, sex chromosomes show sex-biased segregation, with the $Y$ chromosome being limited to males and the $\mathrm{X}$ chromosome showing female-biased transmission (being passed two-thirds of the time through females). Sex-biased transmission of $\mathrm{X}$ and $\mathrm{Y}$ chromosomes implies opportunity for sexually antagonistic selection to redistribute male- and female-beneficial mutations, and for genetic conflicts over sex ratios to arise (124). Indeed, $X$ chromosomes of many species contain a biased set of genes with regard to their sex-specific effects (53). Additionally, the $\mathrm{X}$ chromosome is transcriptionally inactivated during spermatogenesis in many species [meiotic sex chromosome inactivation (MSCI)], and it has been suggested that MSCI evolved either in response to sexually antagonistic selection, driving off spermatogenesis genes from the female-biased X (148), or to prevent the recurrent emergence of meiotic drive elements on the $X$ chromosome (109). Further, hemizygosity of the $\mathrm{X}$ chromosome in males implies that selection will act differentially on $\mathrm{X}$ chromosomes and autosomes, depending on the dominance coefficient of selected mutations. This can result in faster adaptive evolution of $\mathrm{X}$ chromosomes (the faster X effect) (46).

Here, we give an update on recent progress made toward our understanding of sex chromosome evolution in insects, with a particular focus on the diversity of systems in this group.

\section{SEX CHROMOSOMES IN INSECTS}

Insects make up the most diverse group of animals, and equally variable are their mechanisms of sex determination. Among species with sex chromosomes, there are systems with male heterogamety (XY), such as Drosophila melanogaster, or female heterogamety (ZW), such as butterflies and moths. Also, the level of sex chromosome differentiation varies widely among groups. For example, in the scuttle fly Megaselia scalaris, the $\mathrm{X}$ and $\mathrm{Y}$ 
cannot be distinguished under the micrososcope (146), whereas in butterflies, the $\mathrm{W}$ is generally much smaller than the $\mathrm{Z}$ chromosome, forming heterochromatic bodies in the cell (137). In grasshoppers, crickets, and cockroaches, the original Y chromosome has been completely lost, i.e., males carry a single $\mathrm{X}$, whereas females are XX.

\section{Sex Determination}

This diversity of cytological mechanisms determining sex in insects is matched by a similar variety of genetic pathways causing sexual differentiation. In Drosophila, sex is determined by the ratio of $\mathrm{X}: \mathrm{A}$, i.e., the number of $\mathrm{X}$ chromosomes relative to the number of autosomes (48, but see 54 for a slightly modified view). The key genes involved in the pathway are Slx, tra, and $d s x$. The primary signal is the amount of several transcription factors encoded on the $\mathrm{X}$ chromosome (e.g., sis-a, sis-b, sis-c, and run), which determines if Slx is transcribed from the early promotor of Slx (48). Other steps in the pathway include the differential splicing of sex determination genes, resulting in nonfunctional proteins (Slx and tra in males), or in proteins with different $\mathrm{C}$-terminal domains in the two sexes $(d s x)$ (reviewed in 120). In Lepidoptera, the primary signal for sex determination varies, as both a Z-counting and a dominant $\mathrm{W}$ factor exist (137). The $\mathrm{W}$ chromosome of the silkworm, Bombyx mori, for example, contains a dominant factor, fem, that establishes femaleness, with male development being the default state (67). However, also in B. mori, the gene $d s x$ is alternatively spliced in males and females, suggesting that it is involved in sex determination (113). The house fly, Musca domestica, also uses $d s x$ in its sex determination pathway (68, 69), and sex determination genes with structural similarity to $d s x$ are even found outside arthropods, in organisms as distantly related as Caenorhabditis elegans, suggesting an ancient conservation of the gene and its function (98).

Slx, on the other hand, is used only in Drosophila as a sex-specific regulatory gene (although it is also present in B. mori ), whereas the intermediate signal, tra, is shared among other dipterans, such as Lucilia cuprina (50) and M. domestica (69). In the house fly, tra was recently shown to correspond to the female factor F, a key switch gene in the otherwise very plastic sex determination pathway of $M$. domestica (69). Among more distantly related insects, such as Lepidoptera, tra is probably not involved in sex determination (137). This suggests that downstream parts of the Drosophila pathway are more highly conserved among insects, whereas upstream signals have been co-opted only recently (98).

\section{The Drosophila System}

The Drosophila sex chromosomes are probably the best studied system among insects. In $D$. melanogaster, the $\mathrm{Y}$ chromosome is small and entirely heterochromatic and consists mainly of repetitive and transposable element-derived DNA. It contains only about 20 genes, most of which code for male-specific functions such as sperm motility $(35,37,60,141)$. The age of the system is estimated to be at least 60 million years old, based on the evidence that five Y-linked genes are shared among the Drosophila and Sophophora subgenera $(34,85)$.

Most Y-linked genes are megabase sized because of gigantic introns (58), which consist of extended assemblies of degenerate transposable elements and/or large clusters of satellite DNA. Male D. melanogaster lacking a Y chromosome are viable but sterile, indicating that 
these Y-linked genes have functions in male fertility $(30,31)$. Interestingly, all of the Ylinked genes identified in D. melanogaster appear not to have originated from a degenerate $\mathrm{X}$ homolog, but instead were acquired from autosomes (33). This suggests that (almost) all original genes were lost from the $\mathrm{Y}$, and the genes located now on the $\mathrm{Y}$ are subsequent accretions because of a male-specific advantage they confer. Sequence variability in natural populations is substantially reduced on the $\mathrm{Y}$ chromosome of $D$. melanogaster and its close relatives $(20,153)$, which could reflect chromosome-wide selective sweeps that accompanied the fixation of these genes. The lack of homology between the $\mathrm{X}$ and the $\mathrm{Y}$ chromosomes in D. melanogaster has led to the suggestion that the $\mathrm{Y}$ in Drosophila does not correspond to a degenerate $\mathrm{X}$ chromosome. Instead, the $\mathrm{Y}$ chromosome may have been derived from a B chromosome, a supernumerous small chromosome that acquired the ability to pair with the $\mathrm{X}$ and segregate in male flies like a $\mathrm{Y}$ chromosome $(36,64)$. One way to resolve the issue of whether the D. melanogaster Y represents a degenerate copy of the original X chromosome or a secondarily acquired B chromosome would be to establish the ancestral state of sex chromosomes in the Drosophila system by using an outgroup species (assuming that they do not have derived sex chromosome systems as well). If the ancestral system was indeed X0, this would support the idea that the Drosophila $\mathrm{Y}$ was acquired only secondarily and is not a degenerate $\mathrm{X}$.

Apart from the ancient $\mathrm{Y}$ chromosome that is shared among most members of the Drosophila genus, some species have acquired new secondary sex chromosomes (so-called neo-sex chromosomes) that have been inherited as sex chromosomes for different lengths of time and show intermediate stages in the transition from ordinary autosomes into heteromorphic sex chromosomes. A neo-Y/neo-X chromosome pair is formed by a fusion between an autosome and a sex chromosome (Figure 2). As a result of such a fusion, one member of the pair of autosomes (the neo-Y) is inherited from father to son in association with the true $\mathrm{Y}$ chromosome. Its partner (the neo-X) cosegregates with the true $\mathrm{X}$. In Drosophila, the absence of crossing over in males ensures that such a neo-Y chromosome is genetically isolated from its partner (96). In fact, the neo-Y chromosome is completely sheltered from recombination (since it is passed through males only), whereas the neo-X can still recombine in females.

In Drosophila, the ancestral X chromosome corresponds to Muller's element A (according to the nomenclature of Muller) (110). In the lineage leading to Drosophila pseudoobscura, an ancient neo-sex chromosome system arose (approximately 13 mya), when Muller's element $\mathrm{D}$ (chromosome arm 3L in D. melanogaster) became fused to the existing X chromosome, creating a neo-sex chromosome system. The neo-Y chromosome of $D$. pseudoobscura (i.e., the former homolog of the fused chromosome arm) is now degenerated, and the neo-X has acquired full DC by the same molecular mechanisms that are used by the ancestral Drosophila X chromosome $(29,99)$. The origin of the D. pseudoobscura Y, however, is still obscure. If it is indeed a neo-Y chromosome, what happened to the ancestral $\mathrm{Y}$ that is also found in D. melanogaster and $D$. hydei? A striking observation is that homologs of six D. melanogaster Y-linked genes were found to be autosomal in $D$. pseudoobscura (34), mapping in a single contiguous block on the 15 (dot) chromosome (88). Conversely, 15 genes located on the Y chromosome of D. pseudoobscura were assigned to 
genomic locations other than the Y chromosome in D. melanogaster (34), with most of them mapping to genes derived from Muller's element $D$. These observations are consistent with a model where, at roughly the same time as the neo-X formation, the original $D$. pseudoobscura $\mathrm{Y}$ chromosome was translocated onto an autosome and replaced by a new $\mathrm{Y}$ chromosome that was derived from an autosomal segment (34)_possibly the chromosome that is homologous to the neo-X chromosome.

An additional sex chromosome-autosome fusion occurred in the lineage of Drosophila miranda, a close relative of $D$. pseudoobscura. This time, Muller's element C became fused to the Y chromosome $(130,149)$. The neo-Y chromosome of D. miranda still segregates as a normal autosome in Drosophila persimilis and D. pseudoobscura, the closest relatives of $D$. miranda, setting an upper limit of about two million years for the age of this system (149). In Drosophila americana, which belongs to a different lineage within the Drosophila genus, a fusion between the X chromosome and Muller's element B is not fixed species-wide (101, 102), so that there are females with $2 n=10,11$, or 12 chromosomes. Similarly, Drosophila albomicans contains a neo-sex chromosome system that was formed only very recently (13). Thus, the neo-sex chromosomes of Drosophila provide a powerful system that allows the comparative investigation of sex chromosomes at different stages in their evolutionary transition from ordinary autosomes into heteromorphic sex chromosomes.

\section{Sex Chromosomes of other Insects}

Whereas in Drosophila there are only 4-6 chromosome pairs, the sex chromosomes in Lepidoptera make up a much smaller portion of the genome, $n$ being about 30 . Among the most basal Lepidoptera and Trichoptera (caddis flies), females are Z0 and males ZZ, suggesting that this is the ancestral state (137). A fusion between the $\mathrm{Z}$ chromosome and an autosome may have given rise to the $\mathrm{W}$ chromosome early on in the history of Lepidoptera (i.e., the $\mathrm{W}$ chromosome is actually a neo-W), and the $\mathrm{W}$ is now found in about $98 \%$ of all species of that order (137). In some lineages, the W was secondarily lost, or fused with a different autosome, creating a variety of sex chromosome configurations (though males are always the homogametic sex) (reviewed in 137). In the silkworm, B. mori, the W chromosome is heterochromatic, consisting largely of repetitive sequence. The W was not sequenced in the Bombyx genome project (108) — because heterochromatin is difficult to sequence-and its gene content is generally unknown. Only the female factor fem has been mapped onto the $\mathrm{W}$ chromosome of Bombyx (1), although its DNA sequence has not been deciphered. Apart from fem, only anonymous RAPD markers, derived mostly from transposable elements, have been mapped onto the $\mathrm{W}(2)$; however, given that the $\mathrm{W}$ is much smaller than the $\mathrm{Z}$, it probably contains many fewer genes.

Drosophila is not the only fly with interesting sex chromosomes: In $M$. scalaris, the X and $\mathrm{Y}$ are homomorphic and are one of only three chromosome pairs. In some strains of $M$. scalaris, the male sex-determining factor has moved to a different chromosome, the rate of movement being of the order of $10^{-3}$ (138). Such a movement can create new potential sex chromosomes, with the homolog of the chromosome containing the male factor becoming the new proto-X. In the older M. scalaris sex chromosomes, the $\mathrm{X}$ and $\mathrm{Y}$ show some differentiation, such as insertions and deletions in the noncoding sequence, that distinguishes 
the X from the Y (139). Similarly, in the house fly, M. domestica, the male factor M is Ylinked in the standard sex chromosome configuration, but in some populations it is found on one of the five autosomes or even the $\mathrm{X}$ chromosome $(66,127)$. It was recently proposed that the sole function of $\mathrm{M}$ is to intervene in the self-regulation loop of the female factor $\mathrm{F}$ (the tra gene) so that mutations in $\mathrm{F}$ that lead to insensitivity to the presence of $\mathrm{M}$ can result in heterogametic females (69). In the mosquito Anopheles gambiae, males are the heterogametic sex, and the X chromosome is probably the homolog of the Drosophila X (150). However, mosquitos of the genus Aedes have homomorphic sex chromosomes (122), which suggests that the $\mathrm{X}$ chromosomes of $D$. melanogaster and Anopheles were derived independently from the same pair of autosomes. Apart from butterflies, ZW systems are also found in another family of fruit flies, the Tephritidae (51). Little is known about sex chromosome evolution in tephritids; however, they would provide a useful system to disentangle the effects of heterogamety versus the effects of selection on males and females, and to study various aspects of sex chromosome evolution.

\section{W AND Y DEGENERATION}

Striking common features among $\mathrm{Y}$ and $\mathrm{W}$ chromosomes are their paucity of genes, and their tendency to become heterochromatic and to accumulate noncoding sequence or transposable elements (i.e., the $\mathrm{Y}$ or $\mathrm{W}$ chromosome is degenerating) $(26,45,94,119,129)$. This holds true for the human $\mathrm{Y}$ chromosome, which is a clear homolog of the $\mathrm{X}$ and contains only about 80 protein-coding genes (128). Similarly, the D. melanogaster $\mathrm{Y}$ chromosome contains only about a dozen functional genes and is completely heterochromatic. However, it is hard to infer any causes of degeneration if the system is very old because it contains only very few signatures of the processes that led to its degeneration. Young sex chromosome systems that are still in the process of differentiation are more suitable for studying Y degeneration. In particular, the neo-Y chromosome of D. mirandawhich was formed very recently (about 1.5 mya) $(15,16,23)$ and still contains many of its original genes $(8,131)$ - has proven to be a very useful model system to study the degeneration of Y chromosomes.

\section{Molecular Changes on Evolving Y Chromosomes}

Consistent with the idea that selection is less effective in the absence of recombination (41, $45,56,82,111)$, multiple studies have produced ample evidence for reduced adaptation of neo-Y-linked genes in D. miranda. In particular, degeneration of the D. miranda neo-Y appears to be characterized by two types of molecular changes. On one hand, protein-coding genes are degenerating: There has been partial loss of gene activity from the neo-Y, with about half of the genes being clearly nonfunctional, containing frame-shift mutations or stop codons (18). Most remaining genes on the neo-Y show various other signs of degeneration, such as an elevated rate of amino acid substitution (8) and less constraint in regulatory regions (10). Neo-X-linked genes, on the other hand, are highly constrained, and some even show signs of positive selection (7).

A second type of modification occurring on evolving $\mathrm{Y}$ chromosomes is large-scale structural changes. A large proportion of neo-Y-linked DNA in D. miranda is made up of repetitive sequences and transposable elements (at least 20\%); this contrasts with a mere $1 \%$ 
on the neo-X chromosome $(6,18)$. Transposable elements can directly interfere with gene function by inserting into protein-coding genes or their regulatory elements. Alternatively, transposable elements might cause large-scale changes in chromatin structure by initiating chromosomal regions to become heterochromatic and thereby silencing a large number of genes simultaneously $(52,59,93)$. Interestingly, the neo-Y of $D$. miranda is in the process of evolving altered chromatin structure, with large segments having acquired a heterochromatic appearance. Transposable elements show a striking accumulation on the $D$. miranda neo-Y, supporting the link between heterochromatin formation and repetitive DNA. Accumulation of noncoding sequences has also been observed in other young sex chromosome systems, such as the plant Silene latifolia $(38,72)$, in medaka $(86)$, and in stickleback (118), or in the non-recombining region of the papaya sex chromosomes (94), suggesting that this might be one of the first changes that occur when new Y chromosomes arise.

\section{Evolutionary Processes driving Y Chromosome Degeneration}

What processes drive the degeneration of Y chromosomes? As noted by Hill \& Robertson (71), interference among selected sites can lead to a reduction in the efficiency of selection when recombination is low or absent. This can result in an accumulation of deleterious mutations and, in the long term, the degeneration of nonrecombining regions of the genome, such as $\mathrm{Y}$ chromosomes $(11,45)$. Depending on the type and strength of selection, there are different models of the general Hill-Robertson effect: background selection, Muller's ratchet, or selective sweeps. The relative contributions of these processes to Y chromosome degeneration are still under debate $(11,45)$. All models have in common that, as a result of selective interference among mutations, the effective population size $\left(N_{e}\right)$ of a nonrecombining genomic region is reduced; hence, the strength of selection (which is given by $N_{e} s$, where $s$ is the selection coefficient of a mutation) is also reduced. This leads to lower levels of adaptation in low recombination regions of the genome, i.e., the chance for a beneficial mutation to become fixed is decreased, whereas the fixation probability for a deleterious mutation is increased (43).

Under the selective sweep scenario, a beneficial mutation becomes rapidly fixed in a population, dragging with it all mutations that were initially linked to it $(17,79,125)$. Deleterious mutations can become fixed by a selective sweep, provided that the benefit of the selected allele outweighs the effects of the deleterious mutations $(17,125)$. Under the background selection model, strongly deleterious variants are eliminated from a population in a deterministic fashion; without recombination, only chromosomes free of deleterious mutations can survive in the long run (42). This results in a reduction in $N_{e}$-and in turn reduces the efficacy of natural selection-which can lead to an accumulation of slightly deleterious mutations on a nonrecombining Y chromosome (42). A third model, Muller's ratchet, describes the accumulation of deleterious mutations in a finite asexual population: $\mathrm{Y}$ chromosomes vary in the number of deleterious mutations they carry, and the least-loaded mutational class (i.e., the Y chromosomes with the fewest number of mutations) can be lost by chance (39). Without recombination, this class of chromosomes cannot be restored (the ratchet has made one click). Now, the new best class of Y chromosomes can be lost again, 
leading to the continuous accumulation of deleterious mutations and decay in gene function of the Y.

Little is known about the underlying population parameters of processes driving the degeneration of $\mathrm{Y}$ chromosomes (i.e., deleterious and beneficial mutation rates and their associated selection coefficients), making theoretical predictions of the relative contribution of different models to $\mathrm{Y}$ degeneration difficult (55). In addition, processes that affect $\mathrm{Y}$ chromosome degeneration are also likely to change over time (14). For instance, on a young Y chromosome containing many functional genes, deleterious mutations tend to have a larger impact on its evolution, while at intermediate stages of degeneration-when fewer functional genes are present—selective sweeps become more important (14).

Empirical data to test models of $Y$ degeneration are scarce. Initial analysis of patterns of population variation on the neo-Y chromosome of $D$. miranda provided support for the selective sweep model to drive Y degeneration in this species (9). Subsequent analysis, however, suggests that the data might also be compatible with a model of purifying selection alone $(80,81)$. It will be of great interest to further empirically test models of $Y$ degeneration in different biological systems with recently formed $\mathrm{Y}$ chromosomes and to evaluate the hypothesis that the dominant mode of degeneration on a newly formed generich Y chromosome is Muller's ratchet and/or background selection, whereas degeneration due to selective sweeps is highest on Y chromosomes containing an intermediate number of active genes.

Studies focusing on recently derived Y chromosomes find ample evidence for Y chromosome degeneration; this degeneration is probably caused by the large number of genes suddenly placed in a nonrecombining environment and the concomitant selective interference effects. If, however, the Y chromosome is already gene poor (either because it is very old and has lost most of its genes, or because it was small to begin with), it might not necessarily continue to lose genes (14). In a study of the 12 Drosophila species whose genomes were sequenced, Koerich and colleagues (85) found that the Y chromosome shows a marked tendency to gain genes, in contrast to the notion that $Y$ chromosomes are always degenerating. Interestingly, the primate Y chromosome also shows a pattern of rapid turnover of rearrangements but no particular tendency toward overall degeneration (73).

\section{CHROMOSOME-WIDE CHANGES IN PATTERNS OF GENE CONTENT, GENE EXPRESSION, AND RATES OF ADAPTATION ON X CHROMOSOMES}

Conventionally, $\mathrm{X}$ chromosomes are viewed as a static component in the evolutionary process of sex chromosome differentiation, with little change occurring that would distinguish the $\mathrm{X}$ from the autosome from which it was derived. However, genes on $\mathrm{X}$ chromosomes are faced with several unusual properties relative to autosomal genes: Degeneration of the $\mathrm{Y}$ chromosome creates a gene dose problem for $\mathrm{X}$-linked genes in males, $\mathrm{X}$-linked genes are hemizygous in males, and $\mathrm{X}$ chromosomes show sex-biased transmission. Thus, genes on a newly formed $\mathrm{X}$ chromosome may undergo rampant evolutionary changes to adjust to their altered genomic environment. Indeed, rates of adaptation are increased about tenfold on the newly formed neo-X chromosome of $D$. 
miranda, relative to background levels of selection in the genome (19). This suggests that newly formed $\mathrm{X}$ chromosomes are not passive players in the evolutionary process of sex chromosome differentiation but respond adaptively to both their sex-biased transmission and to Y-chromosome degeneration, possibly through the evolution of DC, inactivation of X genes during male meiosis, more efficient incorporation of recessive beneficial mutations, and demasculinization of their gene content.

\section{Dosage Compensation of the X Chromosome}

Degeneration of a nonrecombining $\mathrm{Y}$ or $\mathrm{W}$ chromosome is a general facet of sex chromosome evolution. However, if the heterogametic sex carries only one gene copy of Xor Z-linked genes, this results in an imbalance in the amount of gene product between the $\mathrm{X}$ (Z) and autosomes in males (females). To equalize gene expression levels, dramatically different DC mechanisms have evolved in different organisms: Mammals inactivate one of their two X chromosomes in females, XX hermaphrodite $C$. elegans effectively halves the expression from each $\mathrm{X}$, and male Drosophila increase the transcription of their single X approximately twofold (100).

In D. melanogaster, the mechanism of DC and its components has been extensively studied. D. melanogaster males dosage compensate by up-regulating levels of gene expression of their single $\mathrm{X}$ chromosome through the recruitment of an RNA/protein complex [termed the male-specific lethal (MSL) complex] to their single X chromosome. At least five proteins (MSL-1, MSL-2, MSL-3, MLE, and MOF) and two noncoding RNAs (roX1 and roX2) are part of the MSL complex, which induces acetylation of histone 4 to genes to which it binds $(22,106)$. This results in a global change of chromatin structure, facilitating increased rates of transcription of X-linked genes in males. All MSL proteins need to be present for the MSL complex to form, which is utilized for sex-specific regulation of DC: $S x l$, the femalespecific master sex-determining gene in Drosophila, directly inhibits translation of MSL-2 in females $(22,106)$. Until recently, it remained elusive how the MSL complex specifically targets the $\mathrm{X}$ chromosome, but high-resolution mapping studies have shed light on the mechanism responsible for $\mathrm{X}$ chromosome recognition in male $D$. melanogaster, and support a two-step model of MSL recruitment to the X (Figure 3). The MSL complex is thought to first target over 100 chromatin entry sites [termed high-affinity sites (HAS)] containing specific MSL recognition elements (MRE) on the X chromosome. The HAS represent a subset of the MSL-bound regions in wild-type Drosophila that show a higher affinity for the MSL complex and also recruit the MSL complex under more stringent conditions (such as when inserted into an autosome, or when integral subunits of the MSL complex are missing) $(4,132)$. The HAS contain a guanine-adenine-rich motif, which shows a greater than fourfold enrichment within or $3^{\prime}$ to active genes on the $\mathrm{X}$ chromosome $(4,132)$. After this initial, sequence-specific recognition step, local spreading from entry sites in cis along the $\mathrm{X}$ chromosome leads to MSL binding to many active genes $(4,132)$. Specifically, the chromodomain of the MSL-3 subunit associates with trimethylated histone $\mathrm{H} 3$ lysine 36 (H3K36me3), a chromatin mark that is generated during transcriptional elongation, resulting in bidirectional spreading of the MSL complex from the HAS to flanking regions on the $\mathrm{X}$ chromosome (89). In wild-type embryos and cell lines, approximately half of all genes are bound by the MSL complex, resulting in transcriptional 
up-regulation of X-linked genes through epigenetic modifications $(3,61)$. Little is known about the evolution of DC (i.e., how it is acquired on a recently formed X chromosome), and investigations of neo-X chromosomes in Drosophila will be very informative in this respect $(29,99)$. For example, in D. miranda, it is known that approximately $80 \%$ of all neo-sex genes either are no longer expressed from the neo-Y chromosome or are expressed at a significantly lower level from the neo-Y compared to homologous neo-X loci (12). This loss of gene activity on the neo-Y is associated with the acquisition of DC by many genes or genomic regions on the neo-X, by what appears to be the standard Drosophila molecular mechanism $(29,99)$.

While DC has been extensively studied in D. melanogaster, little is known about the presence or the molecular mechanism of DC in other insect species. The MSL-dependent DC system seems to be unique to the genus Drosophila, and even within Drosophila, alternative mechanisms of DC may be employed (117). In Drosophila busckii males, for instance, MSL proteins do not appear to associate with the X chromosome; instead, the autosome-specific protein painting of fourth is bound to the male $\mathrm{X}$ chromosome of $D$. busckii (90). Intriguingly, sex chromosome systems in which females are the heterogametic sex appear to lack DC. For example, genome-wide expression analysis in B. mori shows that genes on the $\mathrm{Z}$ chromosome are generally expressed at a lower level in females compared to males (151). This suggests that female silkworms lack a chromosome-wide DC system, as do birds, which also have ZW females (76). It is not currently known whether ZW systems generally lack DC mechanisms, and the reasons for this puzzling observation are unclear.

\section{Meiotic Sex Chromosome Inactivation}

Another chromosome-wide phenomenon affecting transcription levels from X-linked genes is MSCI. MSCI refers to the early transcriptional inactivation of the $\mathrm{X}$ chromosome during spermatogenesis, which silences genes residing on the $\mathrm{X}$ (91). MSCI is common among species with XY sex determination [e.g., mammals (140) and C. elegans (25)], but until recently, compelling evidence for MSCI in Drosophila had been lacking and little is known about its molecular basis. Two recent experimental studies provided first direct evidence for the occurrence of MSCI in Drosophila. Global gene expression profiling during different stages of spermatogenesis in D. melanogaster revealed that expression from the $\mathrm{X}$ chromosome relative to autosomes drops in tissues derived from the region of the testes where cells enter the meiotic stage of spermatogenesis, i.e., precisely at that point where $\mathrm{X}$ inactivation is expected to occur (142). However, this microarray analysis revealed that only about $40 \%$ of all X-linked genes are significantly down-regulated, i.e., many X-linked genes are still expressed, and MSCI might not be complete. Another study to test for MSCI in Drosophila used a transgene construct, containing the Escherichia coli lacZ gene and the promotor of an autosomal, testis-specific gene (70). The transgene was randomly inserted into different genomic locations, including the $\mathrm{X}$ chromosome. The expression level of the transgene was consistently higher when it was inserted into an autosomal location, rather than the $\mathrm{X}$, suggesting that expression levels from the $\mathrm{X}$ chromosome were reduced in testes, as expected under MSCI. Thus, chromosome-wide expression of X-linked genes in male Drosophila is modified by two processes: DC and MSCI. Although the evolutionary forces driving DC are easily understood, the significance of MSCI is still obscure. Apart 
from Drosophila, little is known about MSCI in other insect systems, or whether it occurs in female heterogametic systems. Recent results from chicken, however, suggest that MSCI might also occur during $\mathrm{ZW}$ female meiosis (126). It will be of great interest to study the occurance of MSCI in other insect taxa, especially those with ZW systems.

\section{Distribution of Genes Among the Sex Chromosomes}

Apart from changes affecting gene transcription levels on the $\mathrm{X}$ and $\mathrm{Y}$, sex chromosomes are also expected to accumulate a nonrandom gene content. It is straightforward to understand that the $\mathrm{Y}$ chromosome should accumulate genes that are beneficial for males, since the $\mathrm{Y}$ is never under selection in females. Indeed, the Drosophila $\mathrm{Y}$ chromosome contains mainly male function genes $(37,63,83)$, similar to the human $\mathrm{Y}$ chromosome (128). The same reasoning suggests that the $\mathrm{W}$ chromosome should accumulate femalebeneficial genes in ZW systems; however, apart from the fem gene in B. mori, the W gene content is largely unknown in insects, so we do not know whether the gene content of the W chromosome is indeed female biased.

Also, the $\mathrm{X}$ (or Z) chromosome is expected to harbor a nonrandom gene content. In particular, it should be a haven for sexually antagonistic genes - genes that are beneficial for one sex and detrimental for the other $(124,143)$. There are two main reasons as to why this should be the case: First, X chromosomes spend two-thirds of their time in females, i.e., Xlinked genes are subject to selection more often in females than males, and dominant female-beneficial mutations can spread on the $\mathrm{X}$ more easily relative to autosomes. However, $\mathrm{X}$-linked recessive mutations are exposed to selection in males but masked in diploid females, and so we also expect recessive male-beneficial genes to accumulate on the $X$ (124). After a sexually antagonistic gene has become established in the population, selection may lead to the down-regulation of its expression in the sex where it is detrimental, leading to the evolution of sex-biased genes, i.e., genes that are expressed differentially in the two sexes (124). Sex-biased gene expression has been used as a proxy for sexual antagonism and can be directly scored using microarrys or by evaluating expressed sequence tag (EST) libraries. A recent study has for the first time identified a group of candidate genes that experience sexually antagonistic selection in adult $D$. melanogaster using sex-specific fitness assays and genome-wide transcript abundance. About $8 \%$ of all genes were identified as sexually antagonistic, and the $\mathrm{X}$ chromosome is enriched for these genes (75). However, a high proportion of sexually antagonistic genes were found to not show sex-biased expression (75), which may suggest that sex-biased expression represents a footprint of widespread but resolved conflict between the sexes.

In Drosophila, a high proportion of genes are sex biased in expression, with estimates of up to $50 \%(114,123)$, and the gene content of the $\mathrm{X}$ chromosome is indeed highly nonrandom: Several studies have demonstrated that the Drosophila $\mathrm{X}$ is depleted for male-biased genes. This trend was first shown for the $D$. melanogaster $\mathrm{X}$ chromosome $(116,123)$ and recently confirmed for other Drosophila species: The X of D. simulans, D. yakuba, D. ananassae, D. virilis, and $D$. mojavensis all show a striking deficiency of male-biased genes (133). Furthermore, the neo-X chromosome of $D$. pseudoobscura, which is derived from a chromosomal segment that is autosomal in other species, shows the same pattern of 
demasculinization (133). This provides independent evidence of evolutionary forces operating to move male-biased genes off the $\mathrm{X}$ chromosome and that the redistribution of genes can occur over a reasonably short time frame (e.g., $13 \mathrm{MY}$ as for D. pseudoobscura).

What are the mechanisms that lead to a demasculinization of the Drosophila X? Again, the neo-X chromosome of $D$. pseudoobscura is a good system to answer this question because gene movements on and off the neo-X can be compared with movements involving homologous autosomal regions in the other Drosophila species, and ancestral expression patterns can be inferred. It appears that a combination of different factors contributes to the overall demasculinization of the neo-X, including the loss of existing male-biased genes, the lack of emergence of new male-biased genes, and the retroposition of genes (133) - a process by which reverse-transcribed mRNA is integrated into the genome at a different location-as well as duplications of neo-X-linked genes to autosomes (105). Changes in expression patterns of existing genes (from male biased to female biased or unbiased) do not seem to contribute much to the loss of male-biased genes from the neo-X (133). In $D$. melanogaster, there is an excess of retrogenes leaving the $\mathrm{X}$ chromosome compared to the autosomes. Intriguingly, a high proportion of these retroposed genes evolved expression in testis $(28,142)$, suggesting that testis genes might be better off on the autosomes compared to the $\mathrm{X}$.

Sexual antagonism is not the only mechanism that can drive the relocation of spermatogenesis genes off the $\mathrm{X}$. Because transcription is repressed from the $\mathrm{X}$ chromosome during male meiosis (i.e., MSCI) $(70,142)$, the lack of male-biased genes on the Drosophila $\mathrm{X}$ could be due to this mechanistic reason rather than selection acting to move male beneficial genes off the X chromosome (28). However, if MSCI was the only cause for driving male-biased genes off the $X$, the pattern should not be observed for genes expressed in somatic tissues. Indeed, the mammalian X chromosome lacks genes that are expressed during spermatogenesis, whereas genes expressed in other tissues are overrepresented on the $\mathrm{X}$ (84). In contrast, in five of the seven Drosophila species investigated, genes expressed in the male soma are underrepresented on the $\mathrm{X}$-including the neo-X of $D$. pseudoobscura (133) — and male-biased genes that are expressed in testes before the onset of $\mathrm{X}$ inactivation are also underrepresented on the X (133). Hence, MSCI cannot be the sole factor leading to the demasculinization of the $\mathrm{X}$ in Drosophila. A third cause that has been suggested to contribute to the deficiency of male-biased genes on the $\mathrm{X}$ chromosome in Drosophila is DC. However, the deficiency of male-biased genes on the $\mathrm{X}$ does not appear to simply be a consequence of a lack of DC at some genes. Instead, it has been suggested that the DC machinery in Drosophila males directly limits the further up-regulation of already hypertranscribed genes on the $\mathrm{X}$, thereby preventing the evolution of male-biased expression of X-linked genes $(21,145)$.

The distribution of sex-biased genes has also been studied in insect ZW systems. Results based on the silkworm genome sequence show that genes expressed exclusively in testis are overrepresented on the $\mathrm{Z}$ chromosome (5). This is consistent with the idea that dominant, male-beneficial genes are accumulating on the $\mathrm{Z}$ because they are being selected more often in males than females. Furthermore, the lack of DC in B. mori results in Z-linked genes being more highly expressed in males than females (151), which might promote male- 
specific genes to be located on the Z. Similarly, in D. melanogaster, the X contains an overrepresentation of genes expressed in ovaries, but the trend does not hold true for femalebiased genes expressed in the soma (116). In A. gambiae, there is no bias in the distribution among sex-biased genes with respect to the $\mathrm{X}$ chromosome, even though a large fraction of genes is indeed expressed differentially in the two sexes (65). There is no clear a priori reason to expect that sexually antagonistic selection, or the dominance of male- or femalebeneficial mutations, should differ between different insects. It is not known whether MSCI exists or how DC is achieved in Anopheles, but equal expression of X-linked genes in male and female Anopheles suggests that DC exists (136). Hence, results from different systems do not point to a single force operating to modify the gene content of the $\mathrm{X}$ chromosome (i.e., dominance, MSCI, DC), and a combination of different factors, which might vary among species, is likely to act. Studying Drosophila species with neo-sex chromosomes that show incomplete DC or MSCI, or establishing the presence or mechanism of DC and MSCI in other insect species, such as Anopheles, should shed further light onto the evolutionary processes driving the distribution of sex-biased genes in the genome.

\section{Why Dosage Compensation and X Chromosome Inactivation?}

The necessity for dosage compensation is easily understood in relation to Y degeneration: If genes on the $\mathrm{Y}$ chromosome degenerate, males are haploid for $\mathrm{X}$-linked genes.

Hemizygosity often has deleterious effects, especially if it involves many genes or entire chromosomes (92). Dosage deficiencies at X-linked loci thus select for an up-regulation of $\mathrm{X}$ genes in males to restore the proper balance in expression ratios between autosomal and $\mathrm{X}$-linked genes $(42,100,145)$. Different mechanisms to compensate for reduced X-dosage effects have evolved in a variety of taxa, which include up-regulation of the $\mathrm{X}$ chromosome specifically in males (such as in Drosophila) or up-regulation of the $\mathrm{X}$ in both sexes, followed by inactivation of one (e.g., in mammals) or down-regulation of both (e.g., in $C$. elegans) X chromosomes in females $(100,145)$.

Understanding the selective pressures underlying the evolution of MSCI is more challenging. Several models have been proposed for the evolution of MSCI $(104,140)$ and may involve sexually antagonistic selection, silencing of meiotic drivers (or other selfish DNA elements), or avoiding potentially damaging recombination between the heteromorphic sex chromosomes in male meiosis. The SAXI (sexual antagonism and X inactivation) hypothesis used to explain MSCI involves the differential accumulation of sexually antagonistic mutations on $\mathrm{X}$ versus autosomes (148); as a result of female-biased transmission of the $\mathrm{X}$ chromosome, spermatogenesis genes might relocate to autosomes. As the $\mathrm{X}$ chromosome becomes demasculinized, this eventually results in the transcriptional inactivation of the $\mathrm{X}$ during spermatogenesis (148). Indeed, genes with testis-biased expression tend to be underrepresented on the $\mathrm{X}$ (116), and many testis-specific genes have been translocated from the $\mathrm{X}$ to autosomes (95). Although the deficiency of spermatogenesis genes on the Drosophila X chromosome is typically interpreted as a consequence of MSCI, the SAXI hypothesis explains these events by sexually antagonistic selection and regards them as precursors for MSCI to evolve (148). 
The meiotic drive hypothesis for the evolution of MSCI is based on the observation that X chromosomes appear particularly prone to the emergence of meiotic drive elements (77). Mendel's first law of genetics states that two alleles of a heterozygote are transmitted to the next generation at an equal ratio. However, meiotic drive genes-which skew transmission in their own favor-can evolve under certain circumstances, even if they cause harm to the genome as a whole (77). All meiotic drive elements that have been examined in detail entail linkage between a driving allele and an insensitive allele at the responder locus; linkage between these alleles prevents the formation of a suicide combination that can distort against itself and would quickly be eliminated from the population. A lack of recombination implies that sex chromosomes are particularly prone to evolve meiotic drive elements since any gene on the $\mathrm{X}$ (or $\mathrm{Y}$ ) can drive against any responder site on the $\mathrm{Y}$ (or X). Limited opportunity for drivers to emerge exists on the degenerate, gene-poor Y chromosome; however, drive elements might frequently emerge on gene-rich $\mathrm{X}$ chromosomes. Driving $\mathrm{X}$ chromosomes cause female-biased sex ratios $(77,78)$. Given that each organism has one father and one mother, individuals of the rarer sex are more fit on average, driving the evolution of equal sex ratios (57). The driving $\mathrm{X}$ chromosome more frequently winds up in females, and autosomes associated with such $\mathrm{X}$ chromosomes suffer reduced fitness. Thus, autosomal genes that suppress $\mathrm{X}$ chromosome drive are favored, as are resistant variants on the $\mathrm{Y}$ (147). One potential mechanism by which the remaining genome could successfully render many potential drivers on the X inactive is through MSCI. MSCI may thus have evolved to suppress and prevent the recurrent emergence of meiotic drive elements on the $\mathrm{X}(74)$. Although the strength and frequency of meiotic drive elements in a population needed to select for MSCI have not been studied theoretically, sex chromosome drive has evolved repeatedly in the genus Drosophila (77) and could potentially explain the evolution of MSCI.

Alternatively, sex chromosome condensation might have evolved as a meiotic adaptation to prevent pairing and recombination between the differentiated $\mathrm{X}$ and $\mathrm{Y}$ chromosomes and thus protect against detrimental chromosomal damage such as ectopic exchange and doublestrand breaks (140). Under this hypothesis, the heterochromatic conformation of the $\mathrm{X}$ and $\mathrm{Y}$ chromosomes during male meiosis prevents promiscuous recombination but secondarily results in the inactivation of sex chromosomes due to restricted access of the transcriptional machinery to a condensed X. More generally, multiple taxa have evolved mechanisms to silence unpaired DNA during meiosis, which is known as meiotic silencing of unsynapsed chromatin (MSUC). There is strong evidence for MSUC in mammals, where not only the X chromosome is inactivated during spermatogenesis, but also the $\mathrm{Y}$ chromosome and unsynapsed autosomes (140). For example, in XO females, the single X chromosome is inactivated but can escape inactivation by nonhomologous synapsis, and in XYY males, the Y chromosomes escape inactivation (140). Similarly, in C. elegans autosomes that fail to synapse are inactivated along with $\mathrm{X}$ chromosomes during meiosis (25). It is unclear whether MSUC exists in Drosophila. Male meiosis is peculiar in flies because it is achiasmatic; a synaptonemal complex does not form and recombination does not occur, although homologs are paired by other mechanisms (103). Thus, it would seem hazardous to maintain a mechanism for silencing unsynapsed chromatin in cells where all chromosomes would be targeted. Likewise, if males generally lack recombination, there is no need to 
evolve special mechanisms to prevent recombination between the heteromorphic sex chromosomes. This suggests that MSCI in Drosophila must have evolved for other reasons rather than simply being a consequence of transcriptional silencing of un-synapsed chromatin or avoiding the deleterious consequences of illegitimate recombination between heteromorphic sex chromosomes, unless MSCI has evolved prior to the loss of male meiotic recombination in the Drosophila genus.

\section{The Fast X Effect}

Not only levels of expression of X-linked genes are affected by the chromosome's unusual transmission pattern between males and females, but also the rate of evolution of X-linked genes themselves. Since males carry only one X chromosome, recessive X-linked mutations are more often exposed to selection when located on the $\mathrm{X}$ compared to the autosomes.

Hence, the rate of evolution due to positive selection for recessive mutations is increased on the $\mathrm{X}$, and the effect should be particularly strong for male-beneficial genes (46). Evidence for an increased rate of adaptive evolution on the Drosophila $\mathrm{X}$ chromosome is based on the observation of a higher rate of nonsynonymous changes, relative to synonymous changes, for male-biased genes on the $\mathrm{X}$ chromosome compared to the autosomes (152) and higher divergence between X-linked paralogs compared to autosomal paralogs in D. melanogaster (135). Other studies, however, found no difference in the rate of evolution between X-linked and autosomal genes in a D. melanogaster/D. simulans comparison (27), and the faster $\mathrm{X}$ effect might not hold for D. pseudoobscura (107). This is confirmed by a more recent study that found that X-linked genes in the D. pseudoobscura lineage evolve at a similar rate compared to their homologs in the D. melanogaster lineage, where these genes are autosomal (134). If the rate of adaptive evolution on the $\mathrm{X}$ chromosome indeed differs between $D$. melanogaster and $D$. pseudoobscura (which is currently unclear), this could be explained by a larger effective population size of the X, relative to the autosomes, in $D$. melanogaster compared to D. pseudoobscura. Indeed, in D. melanogaster the autosomes and the $\mathrm{X}$ have approximately equal effective population sizes, which has been shown to greatly affect the strength of the faster X effect (144), whereas the X/A ratio in $D$. pseudoobscura is probably much smaller (87). Additionally, a fast $\mathrm{X}$ effect is also not expected if beneficial mutations are derived mainly from standing genetic variation (for example, if an environmental change causes deleterious mutations initially present in the population at mutation-selection balance to become advantageous). Under these conditions, $\mathrm{X}$-linked genes are expected to show lower rates of adaptation, irrespective of the levels of dominance (115). The mixed results obtained from Drosophila studies (reviewed in 121) could result from variation in the dominance coefficients of beneficial mutations or the amount of standing genetic variation, in addition to differences in the effective population size between $\mathrm{X}$ chromosomes and autosomes.

To our knowledge, it is currently unknown whether a fast $\mathrm{Z}$ effect exists in insects with female heterogameity. To date, this question has been studied only in a chicken-zebrafinch comparison. There, the faster evolution of Z-linked genes appears to be a consequence of a reduced population size of the $\mathrm{Z}$ chromosome (i.e., an accumulation of slightly deleterious mutations), rather than due to increased rates of adaptive evolution (97). It will be interesting to study the fast- $Z$ effect in insects, to test whether sexual selection in males 
indeed might lead to the fast- $Z$ effect being stronger than the fast- $X$ effect, as has recently been suggested (112).

\section{CONCLUSION}

Sex chromosomes provide a unique framework to study a wide range of aspects of genome evolution. These include the degeneration of nonrecombining parts of the genome, the selective forces that lead to degeneration, and the timescales over which these changes occur. Gene shuffling in response to differential selection in males and females, different rates of adaptation depending on the dominance of mutations, and epigenetic modifications affecting chromatin structure (MSCI, DC) are further topics that can be addressed using sex chromosomes, integrating the effects of selection on the phenotype, genotype, and epigenetic responses of gene expression. Insects are particularly well suited to study many of these aspects because of the diversity of systems and the different stages of sex chromosome evolution that can be found among them. New sequencing technology will open up the opportunity to study the sex chromosomes and their expression patterns in more obscure groups (such as tephritids), or to obtain sequence data from strains that differ in the location of their sex determination genes. This promises to greatly increase our understanding of the multiple biological processes affecting the evolution of sex chromosomes.

\section{Acknowledgments}

We thank Andy Clark for useful comments on the manuscript. This research was funded by grants from the NIH and a David and Lucile Packard Foundation fellowship to DB.

\section{Glossary}

\author{
Dosage compensation \\ (DC)
}

Male heterogamety

Gene dose

Meiotic sex

chromosome

inactivation (MSCI)

Meiotic drive

Transposable elements a regulatory mechanism to equalize transcription in response to differences in gene dose

a sex chromosome system where the male has one $\mathrm{X}$ and one $\mathrm{Y}$ chromosome and the female has two $\mathrm{X}$ chromosomes. Insects with this type of sex determination include Drosophila and Anopheles

the number of copies present in the genome for a given protein-coding gene

early transcriptional inactivation of the $\mathrm{X}$ chromosome in males during spermatogenesis

any mechanism that causes alleles to be recovered unequally in the gametes of a heterozygote

mobile pieces of DNA that can move around to different positions in the genome 


\section{Satellite DNA}

Selective sweep

Neo-sex chromosomes

Heterochromatin

Y degeneration

Muller's ratchet

Background selection

Effective population

size

Sexually antagonistic
genes

Sex-biased gene

expression

Euchromatin highly repetitive DNA consisting of repetitions of a short

DNA sequence motif

process of an adaptive mutation spreading through a

population, thereby eliminating or reducing variation at linked sites

parts of sex chromosomes formed by the addition of autosomal segments onto existing sex chromosomes

tightly packed form of DNA that consists mainly of genetically inactive satellite sequences

the loss of gene function on an evolving $\mathrm{Y}$ chromosome process by which asexual genomes accumulate deleterious mutations in an irreversible manner in finite populations due to genetic drift

the elimination of neutral variation in a population as a result of selection against deleterious mutations

the number of individuals in an idealized population that experiences the same amount of genetic drift as the real population under consideration

genes that are beneficial to one sex but detrimental to the other

genes transcribed at a higher rate in one sex

lightly packed form of chromatin that is relatively gene rich and often actively transcribed

\section{LITERATURE CITED}

1. Abe H, Fujii T, Tanaka N, Yokoyama T, Kakehashi H, et al. Identification of the femaledetermining region of the $\mathrm{W}$ chromosome in Bombyx mori. Genetica. 2008; 133:269-82. [PubMed: 17901928]

2. Abe H, Mita K, Yasukochi Y, Oshiki T, Shimada T. Retrotransposable elements on the W chromosome of the silkworm, Bombyx mori. Cytogenet Genome Res. 2005; 110:144-51. [PubMed: 16093666]

3. Alekseyenko A, Larschan E, Lai W, Park P, Kuroda M. High-resolution ChIP-chip analysis reveals that the Drosophila MSL complex selectively identifies active genes on the male X chromosome. Genes Dev. 2006; 20:848-57. [PubMed: 16547173]

4. Alekseyenko AA, Peng S, Larschan E, Gorchakov AA, Lee OK, et al. A sequence motif within chromatin entry sites directs MSL establishment on the Drosophila X chromosome. Cell. 2008; 134:599-609. [PubMed: 18724933]

5. Arunkumar KP, Mita K, Nagaraju J. The silkworm Z chromosome is enriched in testis-specific genes. Genetics. 2009; 182:493-501. [PubMed: 19332883]

6. Bachtrog D. Accumulation of spock and worf, two novel non-LTR retrotransposons on the neo-Y chromosome of Drosophila miranda. Mol Biol Evol. 2003; 20:173-81. [PubMed: 12598683] 
7. Bachtrog D. Adaptation shapes patterns of genome evolution in sexual and asexual genomes in Drosophila. Nat Genet. 2003; 34:215-19. [PubMed: 12754509]

8. Bachtrog D. Protein evolution and codon usage bias on the neo-sex chromosomes of Drosophila miranda. Genetics. 2003; 165:1221-32. [PubMed: 14668377]

9. Bachtrog D. Evidence that positive selection drives Y-chromosome degeneration in Drosophila miranda. Nat Genet. 2004; 36:518-22. [PubMed: 15107853]

10. Bachtrog D. Sex chromosome evolution: molecular aspects of Y-chromosome degeneration in Drosophila. Genome Res. 2005; 15:1393-401. [PubMed: 16169921]

11. Bachtrog D. A dynamic view of sex chromosome evolution. Curr Opin Genet Dev. 2006; 16:57885. [PubMed: 17055249]

12. Bachtrog D. Expression profile of a degenerating neo-Y chromosome in Drosophila. Curr Biol. 2006; 16:1694-99. [PubMed: 16950105]

13. Bachtrog D. The speciation history of the Drosophila nasuta complex. Genet Res. 2006; 88:13-26. [PubMed: 17014741]

14. Bachtrog D. The temporal dynamics of processes underlying Y chromosome degeneration. Genetics. 2008; 179:1513-25. [PubMed: 18562655]

15. Bachtrog D, Charlesworth B. Reduced levels of microsatellite variability on the neo-Y chromosome of Drosophila miranda. Curr Biol. 2000; 10:1025-31. [PubMed: 10996069]

16. Bachtrog D, Charlesworth B. Reduced adaptation of a nonrecombining neo-Y chromosome. Nature. 2002; 416:323-26. [PubMed: 11907578]

17. Bachtrog D, Gordo I. Adaptive evolution of asexual populations under Muller's ratchet. Evol Int J Org Evol. 2004; 58:1403-13.

18. Bachtrog D, Hom E, Wong KM, Maside X, de Jong P. Genomic degradation of a young Y chromosome in Drosophila miranda. Genome Biol. 2008; 9:R30. [PubMed: 18269752]

19. Bachtrog D, Jensen J, Zhang Z. Accelerated adaptive evolution on a newly formed X chromosome. PLoS Biol. 2009; 14:e82. [PubMed: 19402745]

20. Bachtrog D, Thornton K, Clark A, Andolfatto P. Extensive introgression of mitochondrial DNA relative to nuclear gene flow in the Drosophila yakuba species group. Evol Int J Org Evol. 2006; 60:292-302.

21. Bachtrog D, Toda N, Lockton S. Dosage compensation and demasculinization of X chromosomes in Drosophila. Curr Biol. 2010; 20:1476-81. [PubMed: 20705467]

22. Baker B, Gorman M, Marin I. Dosage compensation in Drosophila. Annu Rev Genet. 1994; 28:491-521. [PubMed: 7893138]

23. Bartolome C, Charlesworth B. Evolution of amino-acid sequences and codon usage on the Drosophila miranda neo-sex chromosomes. Genetics. 2006; 174:2033-44. [PubMed: 17028318]

24. Barton NH, Charlesworth B. Why sex and recombination? Science. 1998; 281:1986-90. [PubMed: 9748151]

25. Bean CJ, Schaner CE, Kelly WG. Meiotic pairing and imprinted X chromatin assembly in Caenorhabditis elegans. Nat Genet. 2004; 36:100-5. [PubMed: 14702046]

26. Bergero R, Charlesworth D. The evolution of restricted recombination in sex chromosomes. Trends Ecol Evol. 2009; 24:94-102. [PubMed: 19100654]

27. Betancourt A, Presgraves D, Swanson W. A test for faster X evolution in Drosophila. Mol Biol Evol. 2002; 19:1816-19. [PubMed: 12270910]

28. Betran E, Thornton K, Long M. Retroposed new genes out of the X in Drosophila. Genome Res. 2002; 12:1854-59. [PubMed: 12466289]

29. Bone JR, Kuroda MI. Dosage compensation regulatory proteins and the evolution of sex chromosomes in Drosophila. Genetics. 1996; 144:705-13. [PubMed: 8889531]

30. Bridges CB. Non-disjunction as proof of the chromosome theory of heredity. Genetics. 1916; 1:152. [PubMed: 17245850]

31. Brosseau GE. Genetic analysis of the male fertility factors on the Y chromosome of Drosophila melanogaster. Genetics. 1960; 45:257-74. [PubMed: 17247923]

32. Bull, JJ. Evolution of Sex Determining Mechanisms. Menlo Park, CA: Benjamin Cummings; 1983. 
33. Carvalho AB. Origin and evolution of the Drosophila Y chromosome. Curr Opin Genet Dev. 2002; 12:664-68. [PubMed: 12433579]

34. Carvalho AB, Clark AG. Y chromosome of D. pseudoobscura is not homologous to the ancestral Drosophila Y. Science. 2005; 307:108-10. [PubMed: 15528405]

35. Carvalho AB, Dobo BA, Vibranovski MD, Clark AG. Identification of five new genes on the Y chromosome of Drosophila melanogaster. Proc Natl Acad Sci USA. 2001; 98:13225-30. [PubMed: 11687639]

36. Carvalho AB, Koerich LB, Clark AG. Origin and evolution of Y chromosomes: Drosophila tales. Trends Genet. 2009; 25:270-77. [PubMed: 19443075]

37. Carvalho AB, Lazzaro BP, Clark AG. Y chromosomal fertility factors kl-2 and kl-3 of Drosophila melanogaster encode dynein heavy chain polypeptides. Proc Natl Acad Sci USA. 2000; 97:1323944. [PubMed: 11069293]

38. Cermak T, Kubat Z, Hobza R, Koblizkova A, Widmer A, et al. Survey of repetitive sequences in Silene latifolia with respect to their distribution on sex chromosomes. Chromosome Res. 2008; 16:961-76. [PubMed: 18853265]

39. Charlesworth B. Model for evolution of Y chromosomes and dosage compensation. Proc Natl Acad Sci USA. 1978; 75:5618-22. [PubMed: 281711]

40. Charlesworth B. The evolution of sex chromosomes. Science. 1991; 251:1030-33. [PubMed: 1998119]

41. Charlesworth B. The effect of background selection against deleterious mutations on weakly selected, linked variants. Genet Res. 1994; 63:213-27. [PubMed: 8082838]

42. Charlesworth B. The evolution of chromosomal sex determination and dosage compensation. Curr Biol. 1996; 6:149-62. [PubMed: 8673462]

43. Charlesworth B, Betancourt AJ, Kaiser VB, Gordo I. Genetic recombination and molecular evolution. Cold Spring Harbor Symp Quant Biol. 2009; 74:177-86. [PubMed: 19734202]

44. Charlesworth B, Charlesworth D. Model for evolution of dioecy and gynodioecy. Am Nat. 1978; 112:975-97.

45. Charlesworth B, Charlesworth D. The degeneration of Y chromosomes. Philos Trans R Soc Lond B Biol Sci. 2000; 355:1563-72. [PubMed: 11127901]

46. Charlesworth B, Coyne JA, Barton NH. The relative rates of evolution of sex chromosomes and autosomes. Am Nat. 1987; 130:113-46.

47. Charlesworth D, Charlesworth B, Marais G. Steps in the evolution of heteromorphic sex chromosomes. Heredity. 2005; 95:118-28. [PubMed: 15931241]

48. Cline TW. The Drosophila sex determination signal: How do flies count to two? Trends Genet. 1993; 9:385-90. [PubMed: 8310535]

49. Comeron JM. The Hill-Robertson effect: evolutionary consequences of weak selection and linkage in finite populations. Heredity. 2008; 100:19-31. [PubMed: 17878920]

50. Concha C, Scott MJ. Sexual development in Lucilia cuprina (Diptera, Calliphoridae) is controlled by the transformer gene. Genetics. 2009; 182:785-98. [PubMed: 19433631]

51. Davies, N.; Roderick, GK. Dipteran sex chromosomes in evolutionary developmental biology. In: Wiegmann, BM.; Yeates, DK., editors. The Evolutionary Biology of Flies. New York: Columbia Univ. Press; 2005. p. 196-213.

52. Dorer DR, Henikoff S. Expansions of transgene repeats cause heterochromatin formation and gene silencing in Drosophila. Cell. 1994; 77:993-1002. [PubMed: 8020105]

53. Ellegren H, Parsch J. The evolution of sex-biased genes and sex-biased gene expression. Nat Rev Genet. 2007; 8:689-98. [PubMed: 17680007]

54. Erickson JW, Quintero JJ. Indirect effects of ploidy suggest X chromosome dose, not the X:A ratio, signals sex in Drosophila. PLoS Biol. 2007; 5:2821-30.

55. Eyre-Walker A, Keightley P. The distribution of fitness effects of new mutations. Nat Rev Genet. 2007; 8:610-18. [PubMed: 17637733]

56. Felsenstein J. Evolutionary advantage of recombination. Genetics. 1974; 78:737-56. [PubMed: 4448362]

57. Fisher, RA. The Genetical Theory of Natural Selection. Oxford, UK: Oxford Univ. Press; 1930. 
58. Gatti M, Pimpinelli S. Cytological and genetic analysis of the Y chromosome of Drosophila melanogaster 0.1. Organization of the fertility factors. Chromosoma. 1983; 88:349-73.

59. Gatti M, Pimpinelli S. Functional elements in Drosophila melanogaster heterochromatin. Annu Rev Genet. 1992; 26:239-75. [PubMed: 1482113]

60. Gepner J, Hays TS. A fertility region on the Y chromosome of Drosophila melanogaster encodes a dynein microtubule motor. Proc Natl Acad Sci USA. 1993; 90:11132-36. [PubMed: 8248219]

61. Gilfillan G, Straub T, de Wit E, Greil F, Lamm R, et al. Chromosome-wide gene-specific targeting of the Drosophila dosage compensation complex. Genes Dev. 2006; 20:858-70. [PubMed: 16547172]

62. Gordo I, Charlesworth B. Genetic linkage and molecular evolution. Curr Biol. 2001; 11:R684-86. [PubMed: 11553339]

63. Hackstein J, Hochstenbach R. The elusive fertility genes of Drosophila: the ultimate haven for selfish genetic elements. Trends Genet. 1995; 11:195-200. [PubMed: 7785079]

64. Hackstein JHP, Hochstenbach R, HauschteckJungen E, Beukeboom LW. Is the Y chromosome of Drosophila an evolved supernumerary chromosome? Bioessays. 1996; 18:317-23. [PubMed: 8967900]

65. Hahn MW, Lanzaro GC. Female-biased gene expression in the malaria mosquito Anopheles gambiae. Curr Biol. 2005; 15:R192-93. [PubMed: 15797007]

66. Hamm RL, Scott JG. A high frequency of male determining factors in male Musca domestica (Diptera: Muscidae) from Ipswich, Australia. J Med Entomol. 2009; 46:169-72. [PubMed: 19198531]

67. Hashimoto $\mathrm{H}$. The role of the $\mathrm{W}$ chromosome for sex determination in the silkworm, Bombyx mori. Jpn J Genet. 1933; 8:245-58.

68. Hediger M, Burghardt G, Siegenthaler C, Buser N, Hilfiker-Kleiner D, et al. Sex determination in Drosophila melanogaster and Musca domestica converges at the level of the terminal regulator doublesex. Dev Genes Evol. 2004; 214:29-42. [PubMed: 14673649]

69. Hediger M, Henggeler C, Meier N, Perez R, Saccone G, Bopp D. Molecular characterization of the key switch $\mathrm{F}$ provides a basis for understanding the rapid divergence of the sex-determining pathway in the housefly. Genetics. 2010; 184:155-70. [PubMed: 19841093]

70. Hense W, Baines JF, Parsch J. X chromosome inactivation during Drosophila spermatogenesis. PLoS Biol. 2007; 5:2288-95.

71. Hill WG, Robertson A. The effect of linkage on limits to artificial selection. Genet Res. 1966; 8:269-94. [PubMed: 5980116]

72. Hobza R, Lengerova M, Svoboda J, Kubekova H, Kejnovsky E, Vyskot B. An accumulation of tandem DNA repeats on the Y chromosome in Silene latifolia during early stages of sex chromosome evolution. Chromosoma. 2006; 115:376-82. [PubMed: 16612641]

73. Hughes JF, Skaletsky H, Pyntikova T, Graves TA, van Daalen SK, et al. Chimpanzee and human Y chromosomes are remarkably divergent in structure and gene content. Nature. 2010; 463:536-39. [PubMed: 20072128]

74. Hurst LD, Pomiankowski A. Maintaining Mendelism: Might prevention be better than cure? Bioessays. 1991; 13:489-90. [PubMed: 1796911]

75. Innocenti P, Morrow EH. The sexually antagonistic genes of Drosophila melanogaster. PLoS Biol. 2010; 8:e1000335. [PubMed: 20305719]

76. Itoh Y, Melamed E, Yang X, Kampf K, Wang S, et al. Dosage compensation is less effective in birds than in mammals. J Biol. 2007; 6:2. [PubMed: 17352797]

77. Jaenike J. Sex chromosome meiotic drive. Annu Rev Ecol Syst. 2001; 2001:25-49.

78. Jaenike J. X chromosome drive. Curr Biol. 2008; 18:R508-11. [PubMed: 18579088]

79. Johnson T, Barton NH. The effect of deleterious alleles on adaptation in asexual populations. Genetics. 2002; 162:395-411. [PubMed: 12242249]

80. Kaiser VB, Charlesworth B. The effects of deleterious mutations on evolution in nonrecombining genomes. Trends Genet. 2009; 25:9-12. [PubMed: 19027982]

81. Kaiser VB, Charlesworth B. Muller's ratchet and the degeneration of the Drosophila miranda neoY chromosome. Genetics. 2010; 185:339-48. [PubMed: 20215466] 
82. Kaplan NL, Hudson RR, Langley CH. The hitchhiking effect revisited. Genetics. 1989; 123:88799. [PubMed: 2612899]

83. Kennison J. The genetic and cytological organization of the Y chromosome of Drosophila melanogaster. Genetics. 1981; 98:529-48. [PubMed: 17249098]

84. Khil PP, Smirnova NA, Romanienko PJ, Camerini-Otero RD. The mouse X chromosome is enriched for sex-biased genes not subject to selection by meiotic sex chromosome inactivation. Nat Genet. 2004; 36:642-46. [PubMed: 15156144]

85. Koerich LB, Wang X, Clark AG, Carvalho AB. Low conservation of gene content in the Drosophila Y chromosome. Nature. 2008; 456:949-51. [PubMed: 19011613]

86. Kondo M, Hornung U, Nanda I, Imai S, Sasaki T, et al. Genomic organization of the sexdetermining and adjacent regions of the sex chromosomes of medaka. Genome Res. 2006; 16:81526. [PubMed: 16751340]

87. Kovacevic M, Schaeffer SW. Molecular population genetics of X-linked genes in Drosophila pseudoobscura. Genetics. 2000; 156:155-72. [PubMed: 10978282]

88. Larracuente AM, Noor MA, Clark AG. Translocation of Y-linked genes to the dot chromosome in Drosophila pseudoobscura. Mol Biol Evol. 2010; 27:1612-20. [PubMed: 20147437]

89. Larschan E, Alekseyenko AA, Gortchakov AA, Peng S, Li B, et al. MSL complex is attracted to genes marked by H3K36 trimethylation using a sequence-independent mechanism. Mol Cell. 2007; 28:121-33. [PubMed: 17936709]

90. Larsson J, Svensson M, Stenberg P, Mäkitalo M. Painting of fourth in genus Drosophila suggests autosome-specific gene regulation. Proc Natl Acad Sci USA. 2004; 101:9728-33. [PubMed: 15210994]

91. Lifschytz E, Lindsley DL. The role of X-chromosome inactivation during spermatogenesis. Proc Natl Acad Sci USA. 1972; 69:182-86. [PubMed: 4621547]

92. Lindsley DL, Sandler L, Baker BS, Carpenter AT, Denell RE, et al. Segmental aneuploidy and the genetic gross structure of the Drosophila genome. Genetics. 1972; 71:157-84. [PubMed: 4624779]

93. Lippman Z, Gendrel A, Black M, Vaughn M, Dedhia N, et al. Role of transposable elements in heterochromatin and epigenetic control. Nature. 2004; 430:471-76. [PubMed: 15269773]

94. Liu ZY, Moore PH, Ma H, Ackerman CM, Ragiba M, et al. A primitive Y chromosome in papaya marks incipient sex chromosome evolution. Nature. 2004; 427:348-52. [PubMed: 14737167]

95. Long M, Betrán E, Thornton K, Wang W. The origin of new genes: glimpses from the young and old. Nat Rev Genet. 2003; 4:865-75. [PubMed: 14634634]

96. Lucchesi JC. Gene dosage compensation and the evolution of sex chromosomes. Science. 1978; 202:711-16. [PubMed: 715437]

97. Mank JE, Nam K, Ellegren H. Faster-Z evolution is predominantly due to genetic drift. Mol Biol Evol. 2010; 27:661-70. [PubMed: 19926635]

98. Marin I, Baker BS. The evolutionary dynamics of sex determination. Science. 1998; 281:1990-94. [PubMed: 9748152]

99. Marin I, Franke A, Bashaw GJ, Baker BS. The dosage compensation system of Drosophila is coopted by newly evolved X chromosomes. Nature. 1996; 383:160-63. [PubMed: 8774878]

100. Marin I, Siegal ML, Baker BS. The evolution of dosage-compensation mechanisms. Bioessays. 2000; 22:1106-14. [PubMed: 11084626]

101. McAllister BF. Chromosomal and allelic variation in Drosophila americana: selective maintenance of a chromosomal cline. Genome. 2002; 45:13-21. [PubMed: 11908655]

102. McAllister BF, Charlesworth B. Reduced sequence variability on the neo-Y chromosome of Drosophila americana americana. Genetics. 1999; 153:221-33. [PubMed: 10471708]

103. McKee BD. Homolog pairing and segregation in Drosophila meiosis. Genome Dyn. 2009; 5:5668. [PubMed: 18948707]

104. McKee BD, Handel MA. Sex chromosomes, recombination, and chromatin conformation. Chromosoma. 1993; 102:71-80. [PubMed: 8432196]

105. Meisel RP, Han MV, Hahn MW. A complex suite of forces drives gene traffic from Drosophila X chromosomes. Genome Biol Evol. 2009; 2009:176-88. [PubMed: 20333188] 
106. Meller V, Kuroda M. Sex and the single chromosome. Adv Genet. 2002; 46:1-24. [PubMed: 11931222]

107. Metta M, Gudavalli R, Gibert JM, Schlotterer C. No accelerated rate of protein evolution in malebiased Drosophila pseudoobscura genes. Genetics. 2006; 174:411-20. [PubMed: 16816428]

108. Mita K, Kasahara M, Sasaki S, Nagayasu Y, Yamada T, et al. The genome sequence of silkworm, Bombyx mori. DNA Res. 2004; 11:27-35. [PubMed: 15141943]

109. Moore T, Hurst LD, Reik W. Genetic conflict and evolution of mammalian X-chromosome inactivation. Dev Genet. 1995; 17:206-11. [PubMed: 8565327]

110. Muller, HJ. Bearings of the Drosophila work on systematics. In: Huxley, J., editor. The New Systematics. Oxford, UK: Clarendon; 1940. p. 185-268.

111. Muller HJ. The relation of recombination to mutational advance. Mutat Res. 1964; 1:2-9. [PubMed: 14195748]

112. Naurin S, Hansson B, Bensch S, Hasselquist D. Why does dosage compensation differ between XY and ZW taxa? Trends Genet. 2010; 26:15-20. [PubMed: 19963300]

113. Ohbayashi F, Suzuki MG, Mita K, Okano K, Shimada T. A homologue of the Drosophila doublesex gene is transcribed into sex-specific mRNA isoforms in the silkworm, Bombyx mori. Comp Biochem Physiol B Biochem Mol Biol. 2001; 128:145-58. [PubMed: 11163313]

114. Oliver B, Parisi M. Battle of the Xs. Bioessays. 2004; 26:543-48. [PubMed: 15112234]

115. Orr HA, Betancourt AJ. Haldane's sieve and adaptation from the standing genetic variation. Genetics. 2001; 157:875-84. [PubMed: 11157004]

116. Parisi M, Nuttall R, Naiman D, Bouffard G, Malley J, et al. Paucity of genes on the Drosophila X chromosome showing male-biased expression. Science. 2003; 299:697-700. [PubMed: 12511656]

117. Park Y, Kuroda M. Epigenetic aspects of X-chromosome dosage compensation. Science. 2001; 293:1083-85. [PubMed: 11498577]

118. Peichel CL, Ross JA, Matson CK, Dickson M, Grimwood J, et al. The master sex-determination locus in threespine sticklebacks is on a nascent Y chromosome. Curr Biol. 2004; 14:1416-24. [PubMed: 15324658]

119. Pimpinelli S, Berloco M, Fanti L, Dimitri P, Bonaccorsi S, et al. Transposable elements are stable structural components of Drosophila melanogaster heterochromatin. Proc Natl Acad Sci USA. 1995; 92:3804-8. [PubMed: 7731987]

120. Pomiankowski A, Nothiger R, Wilkins A. The evolution of the Drosophila sex-determination pathway. Genetics. 2004; 166:1761-73. [PubMed: 15126396]

121. Presgraves DC. Sex chromosomes and speciation in Drosophila. Trends Genet. 2008; 24:336-43. [PubMed: 18514967]

122. Presgraves D, Orr HA. Haldane's rule in taxa lacking a hemizygous X. Science. 1998; 282:88991. [PubMed: 9841436]

123. Ranz JM, Castillo-Davis CI, Meiklejohn CD, Hartl DL. Sex-dependent gene expression and evolution of the Drosophila transcriptome. Science. 2003; 300:1742-45. [PubMed: 12805547]

124. Rice WR. Sex chromosomes and the evolution of sexual dimorphism. Evolution. 1984; 38:73542.

125. Rice WR. Genetic hitchhiking and the evolution of reduced genetic activity of the Y sex chromosome. Genetics. 1987; 116:161-67. [PubMed: 3596229]

126. Schoenmakers S, Wassenaar E, Hoogerbrugge JW, Laven JS, Grootegoed JA, Baarends WM. Female meiotic sex chromosome inactivation in chicken. PLoS Genet. 2009; 5:e1000466. [PubMed: 19461881]

127. Scott JG, Liu N, Kristensen M, Clark AG. A case for sequencing the genome of Musca domestica (Diptera: Muscidae). J Med Entomol. 2009; 46:175-82. [PubMed: 19351068]

128. Skaletsky H, Kuroda-Kawaguchi T, Minx PJ, Cordum HS, Hillier L, et al. The male-specific region of the human Y chromosome is a mosaic of discrete sequence classes. Nature. 2003; 423:825-37. [PubMed: 12815422] 
129. Steinemann M, Steinemann S. Enigma of Y chromosome degeneration: neo-Y and neo-X chromosomes of Drosophila miranda a model for sex chromosome evolution. Genetica. 1998:102-103. 409-20.

130. Steinemann M, Steinemann S, Lottspeich F. How Y chromosomes become genetically inert. Proc Natl Acad Sci USA. 1993; 90:5737-41. [PubMed: 8390679]

131. Steinemann S, Steinemann M. The Amylase gene cluster on the evolving sex chromosomes of Drosophila miranda. Genetics. 1999; 151:151-61. [PubMed: 9872956]

132. Straub T, Grimaud C, Gilfillan GD, Mitterweger A, Becker PB. The chromosomal high-affinity binding sites for the Drosophila dosage compensation complex. PLoS Genet. 2008; 4:e1000302. [PubMed: 19079572]

133. Sturgill D, Zhang Y, Parisi M, Oliver B. Demasculinization of X chromosomes in the Drosophila genus. Nature. 2007; 450:238-41. [PubMed: 17994090]

134. Thornton K, Bachtrog D, Andolfatto P. X chromosomes and autosomes evolve at similar rates in Drosophila: no evidence for faster X protein evolution. Genome Res. 2006; 16:498-504. [PubMed: 16520459]

135. Thornton K, Long M. Rapid divergence of gene duplicates on the Drosophila melanogaster X chromosome. Mol Biol Evol. 2002; 19:918-25. [PubMed: 12032248]

136. Togawa T, Dunn WA, Emmons AC, Nagao J, Willis JH. Developmental expression patterns of cuticular protein genes with the $\mathrm{R} \& \mathrm{R}$ consensus from Anopheles gambiae. Insect Biochem Mol Biol. 2008; 38:508-19. [PubMed: 18405829]

137. Traut W, Sahara K, Marec F. Sex chromosomes and sex determination in Lepidoptera. Sex Dev. 2007; 1:332-46. [PubMed: 18391545]

138. Traut W, Willhoeft U. A jumping sex determining factor in the fly Megaselia scalaris. Chromosoma. 1990; 99:407-12.

139. Traut W, Wollert B. An X/Y DNA segment from an early stage of sex chromosome differentiation in the fly Megaselia scalaris. Genome. 1998; 41:289-94. [PubMed: 9644837]

140. Turner JM. Meiotic sex chromosome inactivation. Development. 2007; 134:1823-31. [PubMed: 17329371]

141. Vibranovski MD, Koerich LB, Carvalho AB. Two new Y-linked genes in Drosophila melanogaster. Genetics. 2008; 179:2325-27. [PubMed: 18660539]

142. Vibranovski MD, Lopes HF, Karr TL, Long M. Stage-specific expression profiling of Drosophila spermatogenesis suggests that meiotic sex chromosome inactivation drives genomic relocation of testis-expressed genes. PLoS Genet. 2009; 5:e1000731. [PubMed: 19936020]

143. Vicoso B, Charlesworth B. Evolution on the X chromosome: unusual patterns and processes. Nat Rev Genet. 2006; 7:645-53. [PubMed: 16847464]

144. Vicoso B, Charlesworth B. Effective population size and the faster-X effect: an extended model. Evolution. 2009; 63:2413-26. [PubMed: 19473388]

145. Vicoso B, Charlesworth B. The deficit of male-biased genes on the D. melanogaster X chromosome is expression-dependent: a consequence of dosage compensation? J Mol Evol. 2009; 68:576-83. [PubMed: 19407921]

146. Willhoeft U, Traut W. Molecular differentiation of the homomorphic sex chromosomes in Megaselia scalaris (Diptera) detected by random DNA probes. Chromosoma. 1990; 99:237-42. [PubMed: 2209225]

147. Wu CI. The fate of autosomal modifiers of the sex-ratio trait in Drosophila and other sex-linked meiotic drive systems. Theor Popul Biol. 1983; 24:107-20. [PubMed: 6658686]

148. Wu CI, Xu EY. Sexual antagonism and X inactivation - the SAXI hypothesis. Trends Genet. 2003; 19:243-47. [PubMed: 12711214]

149. Yi SJ, Charlesworth B. Contrasting patterns of molecular evolution of the genes on the new and old sex chromosomes of Drosophila miranda. Mol Biol Evol. 2000; 17:703-17. [PubMed: 10779531]

150. Zdobnov EM, von Mering C, Letunic I, Torrents D, Suyama M, et al. Comparative genome and proteome analysis of Anopheles gambiae and Drosophila melanogaster. Science. 2002; 298:14959. [PubMed: 12364792] 
151. Zha X, Xia Q, Duan J, Wang C, He N, Xiang Z. Dosage analysis of Z chromosome genes using microarray in silkworm, Bombyx mori. Insect Biochem Mol Biol. 2009; 39:315-21. [PubMed: 19150406]

152. Zhang Z, Hambuch TM, Parsch J. Molecular evolution of sex-biased genes in Drosophila. Mol Biol Evol. 2004; 21:2130-39. [PubMed: 15282334]

153. Zurovcova M, Eanes WF. Lack of nucleotide polymorphism in the Y-linked sperm flagellar dynein gene Dhc-Yh3 of Drosophila melanogaster and D. simulans. Genetics. 1999; 153:170915. [PubMed: 10581278] 
a

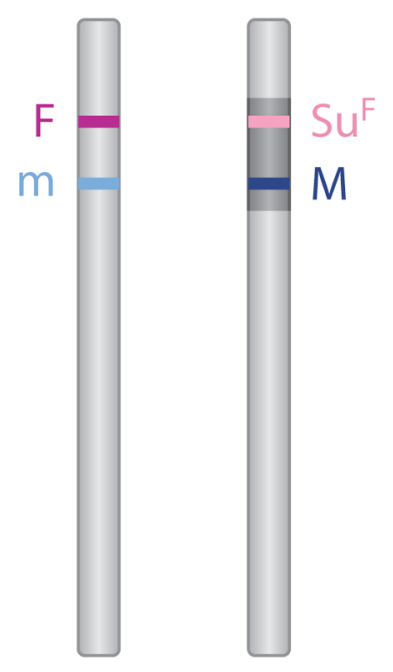

Proto-X Proto-Y

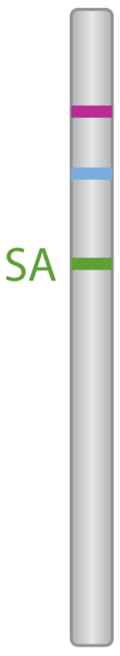

$\mathbf{X}$ b

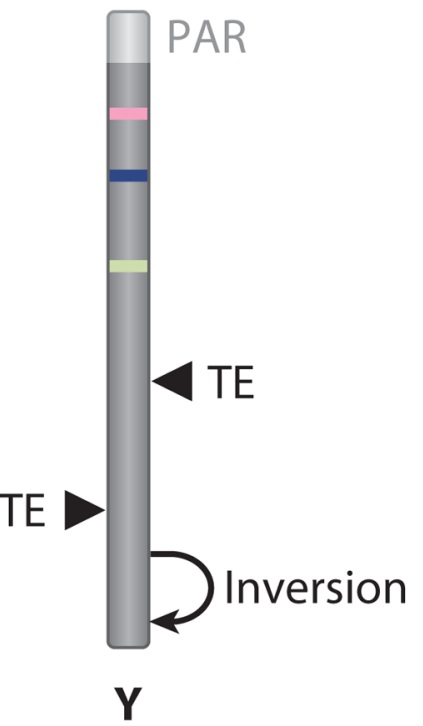

$\mathrm{M}_{2}$

$M_{2}$

$M_{2}$

Figure 1.

Model of the evolution of sex chromosomes from a hermaphroditic state $(40,44)$. (a) A homologous pair of autosomes acquires two sex-determining loci, thereby turning into a proto- $\mathrm{X}$ and proto-Y chromosome; the proto- $\mathrm{Y}$ carries a dominant female suppressor $\left(\mathrm{Su}^{\mathrm{F}}\right)$ and male fertility locus (M), and the proto-X carries a female fertility (F) and male sterility (m) locus. Recombination becomes restricted between these loci (dark gray) to prevent the production of infertile neuter individuals. $(b)$ Recombination suppression extends as a result of the insertion of transposable elements (TEs) and other noncoding sequences on the Y, chromosomal rearrangements, and the acquisition of sexually antagonistic genes (SA) that carry different alleles on the $\mathrm{X}$ and $\mathrm{Y}$ chromosomes. The $\mathrm{X}$ and $\mathrm{Y}$ only recombine in a small region, the pseudoautosomal region (PAR). (c) The Y chromosome accumulates further male fertility genes $\left(\mathrm{M}_{2}\right)$, whereas the $\mathrm{X}$ accumulates sexually antagonistic (femalebeneficial or male-beneficial) genes (SA). 
a

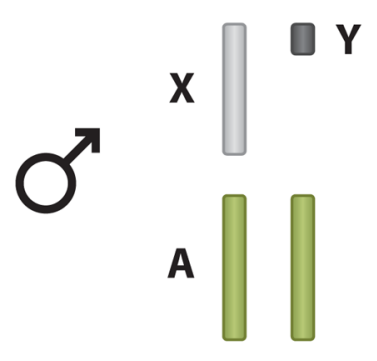

ㅇ

A

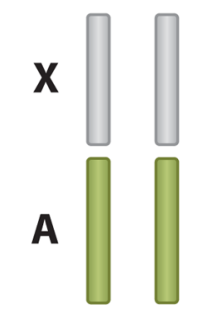

b
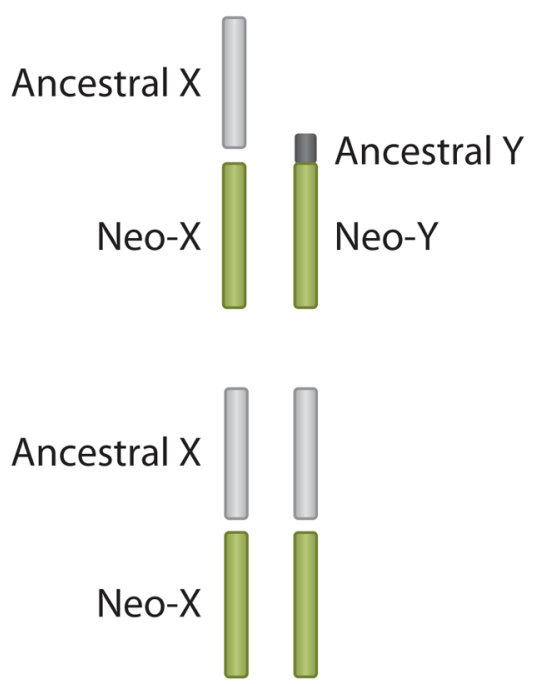

C
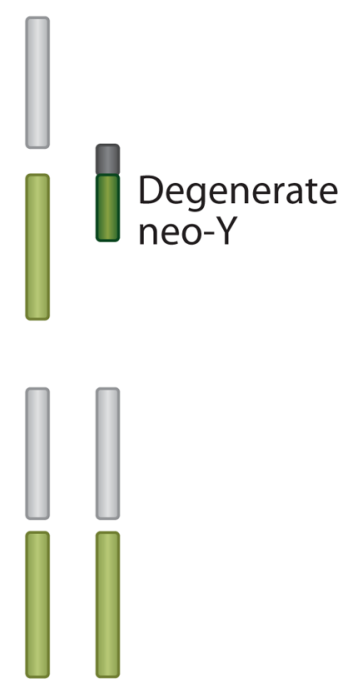

Figure 2.

Evolution of neo-sex chromosomes in Drosophila. (a) The karyotype of the male is XY AA, and the female is XX AA. (b) The Y chromosome fuses with one of the autosomes, creating a neo-Y chromosome that segregates from the neo-X in males. The neo-X behaves like a normal autosome in females. The lack of recombination in male Drosophila ensures that the neo-Y chromosome is genetically isolated from the neo-X; i.e., there is no genetic exchange between these chromosomes (which implies that the neo-Y chromosome is completely sheltered from recombination). (c) After some time, the nonrecombining neo-Y will degenerate, just like the original Y chromosome did. 


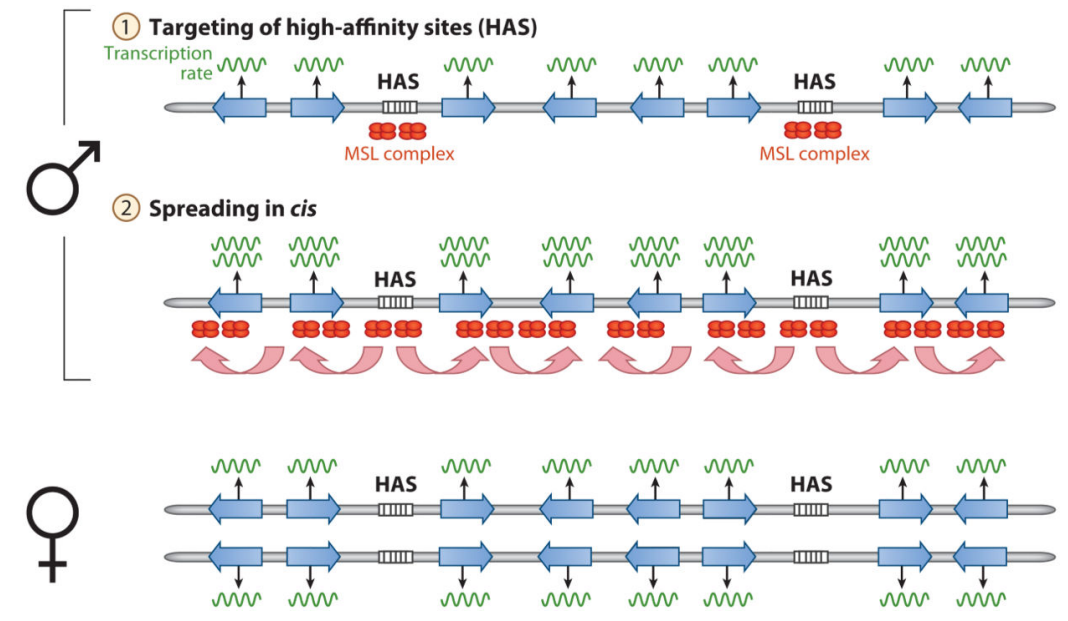

Figure 3.

Two-step model of dosage compensation in Drosophila melanogaster. In males, highaffinity sites (HAS) on the X chromosome are bound by the MSL complex in a sequencespecific manner. Binding of the complex spreads in cis from the entry site and activates transcription of X-linked genes by acetylation of their histone proteins. A higher rate of transcription from the $\mathrm{X}$ in males is indicated by larger amounts of mRNA produced ( green lines). In females, the male-specific lethal (MSL) complex is not assembled. 